\title{
The Synergistic Interplay between Vitamins $D$ and $K$ for Bone and Cardiovascular Health: A Narrative Review
}

\author{
Adriana J. van Ballegooijen, ${ }^{1}$ Stefan Pilz, ${ }^{2,3}$ Andreas Tomaschitz, ${ }^{4}$ \\ Martin R. Grübler, ${ }^{2,5}$ and Nicolas Verheyen ${ }^{6}$ \\ ${ }^{1}$ Department of Health Sciences, Vrije Universiteit Amsterdam and the Amsterdam Public Health Research Institute, \\ Amsterdam, Netherlands \\ ${ }^{2}$ Division of Endocrinology and Diabetology, Department of Internal Medicine, Medical University of Graz, Graz, Austria \\ ${ }^{3}$ Department of Epidemiology and Biostatistics, VU University Medical Center and the Amsterdam Public Health Research Institute, \\ Amsterdam, Netherlands \\ ${ }^{4}$ Bad Gleichenberg Clinic, Bad Gleichenberg, Austria \\ ${ }^{5}$ Department of Cardiology, Swiss Cardiovascular Center Bern, Bern University Hospital, University of Bern, Bern, Switzerland \\ ${ }^{6}$ Department of Cardiology, Medical University of Graz, Graz, Austria
}

Correspondence should be addressed to Adriana J. van Ballegooijen; hanne.van.ballegooijen@vu.nl

Received 2 June 2017; Accepted 17 August 2017; Published 12 September 2017

Academic Editor: Constantinos Pantos

Copyright (c) 2017 Adriana J. van Ballegooijen et al. This is an open access article distributed under the Creative Commons Attribution License, which permits unrestricted use, distribution, and reproduction in any medium, provided the original work is properly cited.

\begin{abstract}
Vitamins $\mathrm{D}$ and $\mathrm{K}$ are both fat-soluble vitamins and play a central role in calcium metabolism. Vitamin D promotes the production of vitamin K-dependent proteins, which require vitamin $\mathrm{K}$ for carboxylation in order to function properly. The purpose of this review is to summarize available evidence of the synergistic interplay between vitamins $\mathrm{D}$ and $\mathrm{K}$ on bone and cardiovascular health. Animal and human studies suggest that optimal concentrations of both vitamin $\mathrm{D}$ and vitamin $\mathrm{K}$ are beneficial for bone and cardiovascular health as supported by genetic, molecular, cellular, and human studies. Most clinical trials studied vitamin $\mathrm{D}$ and $\mathrm{K}$ supplementation with bone health in postmenopausal women. Few intervention trials studied vitamin $\mathrm{D}$ and $\mathrm{K}$ supplementation with cardiovascular-related outcomes. These limited studies indicate that joint supplementation might be beneficial for cardiovascular health. Current evidence supports the notion that joint supplementation of vitamins D and K might be more effective than the consumption of either alone for bone and cardiovascular health. As more is discovered about the powerful combination of vitamins $\mathrm{D}$ and $\mathrm{K}$, it gives a renewed reason to eat a healthy diet including a variety of foods such as vegetables and fermented dairy for bone and cardiovascular health.
\end{abstract}

\section{Introduction}

Worldwide, a large group of people is prescribed to a supplemental regime of both vitamin $\mathrm{D}$ and calcium. In Europe, depending on a country and sex, between 1 and $66 \%$ of the adult population use vitamin D supplements $[1,2]$. Over the last decade, large vitamin D supplementation is promoted to restore 25-hydroxyvitamin D $(25(\mathrm{OH}) \mathrm{D})$ concentrations and is considered to be safe with doses up to 4000 international units (IU) per day [3]. However, little is known about potential long-term high-dose vitamin D supplementation $[2,4]$.
Vitamin $\mathrm{D}$ is a fat-soluble vitamin that can be ingested by foods such as fatty fish, dairy products, and eggs, but is mainly synthesized by the human skin when exposed to sunlight. In the liver, vitamin $\mathrm{D}$ is hydroxylated to $25(\mathrm{OH}) \mathrm{D}$, the main circulating vitamin $\mathrm{D}$ metabolite that is measured to assess and classify vitamin D status. Circulating $25(\mathrm{OH}) \mathrm{D}$ is further metabolized by the kidney for full biological activity into its most active form 1,25-dihydroxyvitamin $\mathrm{D}(1,25(\mathrm{OH}) \mathrm{D})$ also known as calcitriol. Calcitriol is also produced endogenously by extrarenal production through peripheral 1- $\alpha$-hydroxylase and has positive effects on immune function and anticancer activity [5-7]. Vitamin D 
plays a main role in regulating calcium metabolism by increasing intestinal calcium absorption [8]. Ample evidence recommends vitamin $\mathrm{D}$ supplementation for the prevention of falls and fractures [9, 10]; however, evidence suggests calcium precipitation in the vasculature and other potential side effects [4, 11-14].

Vitamin $\mathrm{K}$ is another fat-soluble vitamin that exists in two forms of vitamin $\mathrm{K}$ : vitamin $\mathrm{K}_{1}$ (phylloquinone, mainly found in green leafy vegetables) and vitamin $\mathrm{K}_{2}$ (menaquinone, mainly found in fermented dairy and produced by lactic acid bacteria in the intestine) [15]. Vitamin K stores are limited, but they can be recycled to a certain extent [16]. Vitamin $K_{1}$ is principally transported to the liver, regulating the production of coagulation factors, while vitamin $K_{2}$ is transported to extrahepatic tissues, such as bone and the vascular wall, regulating the activity of matrix Gla protein (MGP) and osteocalcin (bone Gla protein)-the main vitamin $\mathrm{K}$-dependent proteins. They require vitamin $\mathrm{K}$ for carboxylation in order to function properly. When circulating concentrations of vitamin $\mathrm{K}$ are insufficient, a greater proportion of MGP and osteocalcin remain uncarboxylated, which is associated with unfavorable outcomes such as cardiovascular disease, lower BMD, and osteoporosis [17]. The current recommendation for vitamin $\mathrm{K}_{1}$ intake is $70 \mu \mathrm{g} /$ day for all adults defined by an adequate intake [18]. This amount is solely based on maintaining coagulation function and might not be enough for optimal carboxylation of other vitamin K-dependent proteins, which require higher amounts of vitamin $\mathrm{K}$ [19].

The role of vitamin $\mathrm{K}$ in cardiovascular health has mainly been studied in isolation [20]; however, a growing body of evidence suggests a synergistic effect of vitamin K combined with vitamin D [21-26]. Vitamin D promotes the production of vitamin $\mathrm{K}$-dependent proteins, as shown in rats by Karl et al. already in 1985 [27]. These findings cannot be explained by our current understanding of the biochemical role of vitamin $K$, but suggest that vitamin $D$ may influence vitamin K-dependent proteins [28].

The purpose of this narrative review is to summarize available evidence in the field of the synergistic interplay between vitamins $\mathrm{D}$ and $\mathrm{K}$ on bone and cardiovascular health. The primary focus is on the general population and includes observational studies that investigated both vitamin $\mathrm{D}$ and vitamin $\mathrm{K}$ status with outcome measures and supplementation studies that administered both vitamins $\mathrm{D}$ and $\mathrm{K}$.

\section{Interaction of Vitamins $\mathrm{D}$ and $\mathrm{K}$ for Bone Health}

2.1. Experimental Studies. In experimental models, the exploration of the interaction between vitamins $\mathrm{D}$ and $\mathrm{K}$ on bone health is ongoing for decades and a fair amount of literature is available. Recent understanding suggests that vitamin $\mathrm{D}$ enhances vitamin $\mathrm{K}$-dependent bone protein concentrations and induces bone formation in vitro [29-31] with stimulation of osteoblast-specific gene expression [32]. Osteoblast-specific expression of osteocalcin is controlled at the transcriptional level by $1,25(\mathrm{OH}) \mathrm{D}$ through the $1,25(\mathrm{OH}) \mathrm{D}$-responsive element within the promoter of the osteocalcin gene [32]. The underlying mechanism of mineralization induced by vitamin $\mathrm{K}$ in the presence of $1,25(\mathrm{OH}) \mathrm{D}$ was different from vitamin $\mathrm{K}$ alone [33]. In rats, 1,25(OH)D receptor binding can undergo gamma-carboxylation in the presence of vitamin $\mathrm{K}$. This means that $1,25(\mathrm{OH}) \mathrm{D}$ receptor carboxylation can potentially modify the intrinsic biochemical properties of the nuclear receptors and modulates its binding to DNA [34].

The effect of $1,25(\mathrm{OH}) \mathrm{D}$ and warfarin-a vitamin $\mathrm{K}$ antagonist-on the vitamin $\mathrm{K}$ cycle was studied in cultured osteoblasts [26]. Epoxide reductase, one of the key enzymes in the vitamin $\mathrm{K}$ cycle, was strongly inhibited by warfarin, whereas it was not affected by $1,25(\mathrm{OH}) \mathrm{D}$, meaning that the vitamin $\mathrm{K}$ metabolic cycle functions normally in human osteoblasts.

Human osteoblast cell cultures indicate that glycoxidation interferes with the maturation of osteoblasts; however, this process may be counterbalanced by adding vitamins D and $\mathrm{K}$, which reverses the detrimental glycoxidation on several bone markers [35]. Therefore, the addition of vitamins $\mathrm{D}$ and $\mathrm{K}$ may induce important biochemical changes in bone, which may exert therapeutic effects on bone metabolic diseases such as osteoporosis [36].

2.2. Animal Models. A growing body of evidence is also documenting the interaction between vitamins $\mathrm{D}$ and $\mathrm{K}$ in animal models. The effect of vitamin $\mathrm{K}$ of bone mineralization is enhanced by plasma $25(\mathrm{OH}) \mathrm{D}$ concentration. Vitamin $\mathrm{K}$ was administered to prevent osteoporosis in ovariectomized rats, but bone loss was only prevented in rats fed with a diet containing vitamin $\mathrm{D}$ or vitamin $\mathrm{D}$ supplementation [37, 38]. These findings suggest that combined treatment with vitamins $\mathrm{D}$ and $\mathrm{K}$ is more effective than vitamin $\mathrm{K}$ alone particularly in the early phase of estrogen deficiency after menopause.

Vitamin $\mathrm{K}$ and vitamin D supplementation on calcium balance was investigated in young rats fed with a normal or low calcium diet, plus vitamin $\mathrm{K}$ and/or vitamin $\mathrm{D}$ [39]. Vitamin $\mathrm{K}$ supplementation promoted the reduction in urinary calcium excretion and stimulated intestinal calcium absorption in rats on a normal calcium diet. Vitamin D supplementation stimulated intestinal calcium absorption with prevention of the abnormal elevation of serum PTH concentrations, prevented hypocalcemia in rats fed with a low calcium diet, and stimulated intestinal calcium absorption in rats fed with a normal calcium diet. The stimulation of intestinal calcium absorption was associated with increased 1,25(OH)D concentrations. An additive effect of vitamin $\mathrm{K}$ and vitamin $\mathrm{D}$ on intestinal calcium absorption was only found in rats fed with a normal calcium diet. This study shows the differential effects of vitamin $\mathrm{K}$ and vitamin $\mathrm{D}$ supplementation on calcium balance in young rats fed with a normal or low calcium diet.

2.3. Observational Evidence. Human evidence for the role of $1,25(\mathrm{OH}) \mathrm{D}$ in stimulating vitamin $\mathrm{K}$-dependent proteins is scarce. In hemodialysis patients, vitamin D analog users had much higher concentrations of bone Gla protein (BGP) than nonusers indicating that vitamin $\mathrm{D}$ administration 
may play a role in stimulating vitamin $\mathrm{K}$-dependent protein activity [40]. More research on the stimulating role of vitamin $\mathrm{D}$ on vitamin $\mathrm{K}$-dependent proteins is urgently needed to study the underlying mechanisms.

Some observational studies support the hypothesis that optimal concentrations of both vitamins $\mathrm{D}$ and $\mathrm{K}$ support bone mineralization and lower fracture risk. In a crosssectional study among Japanese older men, lower 25(OH)D and vitamin $\mathrm{K}_{1}$ concentrations were concomitantly associated with $\mathrm{BMD}$, indicating a nonestrogen-dependent pathway in men [41]. In a case-control study of 184 Norwegian older adults, the combination of low vitamin $\mathrm{K}_{1}$ and low $25(\mathrm{OH}) \mathrm{D}$ was synergistically associated with hip fractures: odds ratio 7.6 (95\% CI 2.3, 26.7) [42]. In the NOREPOS study, another Norwegian population study, similar results were observed among 1318 older adults [43]. During 8.2-year follow-up, the combination of both low vitamin $\mathrm{D}$ and $\mathrm{K}_{1}$ concentrations was associated with a greater hip fracture risk, hazard ratio 1.41 (95\% CI 1.09, 1.82), compared to the high vitamin $\mathrm{D}$ and vitamin $\mathrm{K}$ category. No increased risk was observed in the groups low in 1 vitamin only. These results indicate that the combination of low concentrations of vitamin $\mathrm{K}_{1}$ and $25(\mathrm{OH}) \mathrm{D}$ is associated with increased risk of hip fractures.

2.4. Human Intervention Studies. A small study among 15 healthy women indicated that 3 weeks of supplementation of $20 \mathrm{ml}$ extra virgin olive oil enriched with vitamins $\mathrm{D}, \mathrm{K}$, and $B_{6}$ resulted in lower concentrations of uncarboxylated osteocalcin [44]. This means that a vitaminized oil can influence vitamin K-dependent proteins within multiple weeks.

An increasing amount of randomized controlled trials have demonstrated the combined effects of vitamins $\mathrm{D}$ and $\mathrm{K}$ on postmenopausal osteoporosis mostly pursued in Japan with a study duration between 8 weeks and 3 years (Table 1). A randomized trial with 4 arms (diet, menaquinone- 4 , cholecalciferol, and menaquinone- $4+$ cholecalciferol) showed that only the vitamin $K$ plus vitamin $D$ arm increased BMD [45]. Similar results were found in another trial with postmenopausal women with osteoporosis $\geq 5$ years after menopause [46]. After 2 years of follow-up, the longitudinal changes in BMD were significant compared with those in the calcium lactate-, vitamin $\mathrm{D}$-, and vitamin $\mathrm{K}$-only groups $(P<0.001)$. A modest synergistic effect of vitamins $\mathrm{D}$ and $\mathrm{K}$ was found after 2 years in healthy older women from nutritionally relevant intakes of vitamin $\mathrm{K}_{1}$ together with supplements of calcium plus vitamin $\mathrm{D}_{3}$ on bone mineral concentration compared to either vitamin $\mathrm{D}$ or $\mathrm{K}$ alone or placebo [47]. The complementary effect of vitamin $\mathrm{K}_{1}(1 \mathrm{mg} /$ day $)$ and a mineral + vitamin $\mathrm{D}$ supplement $(8 \mu \mathrm{g} /$ day $)$ was most effective in reducing bone loss at the femoral neck after 3 years among postmenopausal women versus vitamin $\mathrm{D}$ alone or placebo [48]. The addition of vitamin $\mathrm{K}$ to vitamin $\mathrm{D}$ and calcium supplements compared to vitamin $\mathrm{D}$ and calcium alone in postmenopausal Korean women increased $\mathrm{BMD}$ and reduced uncarboxylated osteocalcin concentrations after 6 months compared to vitamin D and calcium alone [49]. In postmenopausal women, 1 year of oral supplementation with extra virgin olive oil enriched with vitamins $D_{3}, K_{1}$, and $B_{6}$ or extra virgin olive oil reduced uncarboxylated osteocalcin concentrations and increased the T-score of BMD [50]. These findings indicate that combined administration of vitamin $\mathrm{D}$ and vitamin $\mathrm{K}$ appears to be useful in increasing BMD in postmenopausal women. It should be noted that these studies found beneficial effects at some but not all BMD sites measured. Furthermore, treatment with vitamins $\mathrm{D}$ and $\mathrm{K}$ with calcium increased BMD in older female patients with Alzheimer's disease and led to the prevention of nonvertebral fracture odds ratio: 7.5 (95\% CI 5.6, 10.1); however, no placebo capsules were administered, hampering the interpretation of the results [51].

Not all studies observed synergistic effects of vitamin D and $\mathrm{K}$ supplementation. A small study among adults with Crohn's disease in Ireland showed generally no effect of combined vitamin $\mathrm{D}$ and $\mathrm{K}$ supplementation versus placebo on bone mass after 1 year, except a modest increase in bone mass of the total radius [52]. Among healthy women, 1 year of vitamin $\mathrm{D}$ and calcium + vitamin $\mathrm{K}$ supplementation either by phylloquinone or menaquinone- 4 supplementation had no effect on BMD compared to calcium and vitamin $\mathrm{D}$ alone [53]. This study does not support a combined role for vitamin $\mathrm{D}+\mathrm{K}$ supplementation in osteoporosis prevention; however, the relatively short study duration and the inclusion of healthy women could explain the null finding. It is however questionable if BMD can be improved in 12 months since changes in $\mathrm{BMD}$ usually require at least 1 year of follow-up time.

Among healthy older men and women, no difference was observed between multivitamin and calcium and vitamin $\mathrm{D}$ compared with the addition of vitamin $\mathrm{K}$ on BMD after 3 years [19]. An additive effect was noticeable for decreased percentage of uncarboxylated osteocalcin, which indicates an improved vitamin $\mathrm{K}$ status in the treatment group.

The ECKO trial among postmenopausal women with osteopenia showed no beneficial effect of vitamin D and calcium + vitamin $\mathrm{K}$ supplementation versus vitamin $\mathrm{D}$ and calcium alone after 2 years of follow-up in vitamin Dsufficient women [54]. However, the risk of fractures-a clinically more meaningful endpoint-was lower in the vitamin D and calcium + vitamin K groups: hazard ratio 0.41 (95 CI $0.1,1.18)$ at 2 years and $0.45(95 \%$ CI $0.20,0.98)$ after 4 years of follow-up. This result on fracture risk indicates that bone quality rather than quantity is more important as not all trials showed synergistic effects of vitamin $\mathrm{D}$ and $\mathrm{K}$ supplementation on bone mineral density.

The protective effect of vitamin $\mathrm{D}$ with $\mathrm{K}$ on prednisolone-induced loss of BMD in patients with chronic glomerulonephritis after 8 weeks of treatment was similar in the vitamin D-only group [55], meaning that the addition of vitamin $\mathrm{K}$ had no synergistic effect. The elevation in serum calcium concentrations in the vitamin D group was, however, attenuated in the vitamin $\mathrm{D}+\mathrm{K}$ group.

Taken together the evidence for combined vitamin $\mathrm{D}$ and K supplementation, the majority of the studies found beneficial effects for BMD among postmenopausal women. 







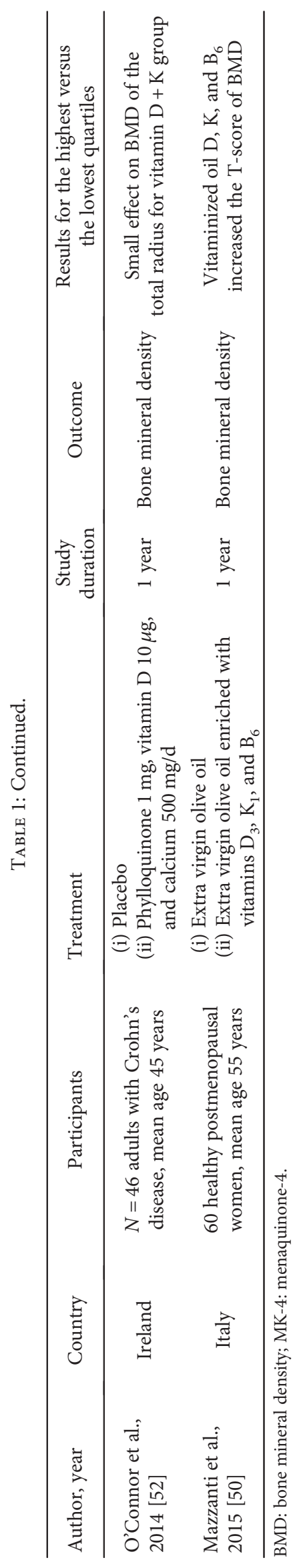




\section{Interaction between Vitamins $D$ and $K$ for Cardiovascular Health}

Besides bone health, also, the interaction between vitamins $\mathrm{D}$ and $\mathrm{K}$ with regard to cardiovascular health receives growing research interest. MGP - the vascular marker of vitamin $\mathrm{K}$ status-needs $\boldsymbol{\gamma}$-glutamate carboxylation to inhibit vascular calcification [56]. In an experimental rat model, warfarin was administered to induce vitamin $\mathrm{K}$ deficiency and caused arterial calcification [57], which was accelerated when given toxic doses of vitamin $\mathrm{D}$ and resulted in premature death.

The Czech MONICA study cross-sectionally observed that subjects in the highest quartile of dephosphorylateduncarboxylated MGP (dp-ucMGP) plus the lowest quartile of $25(\mathrm{OH}) \mathrm{D}$ concentrations had the highest pulse wave velocity in middle-aged healthy adults [58]. Further, potential interaction between vitamin $\mathrm{K}$ status and polymorphisms of the vitamin $\mathrm{D}$ receptors was investigated. Pulse wave velocity was higher with the number of G-allele polymorphisms and highest in the top quartile of dp-ucMGP for the GG vitamin D receptor genotype.

A Dutch prospective cohort indicates that the combination of low vitamin $\mathrm{D}<50 \mathrm{mmol} / \mathrm{L}$ and low $\mathrm{K}$ status $\geq 323 \mathrm{~m}$ $\mathrm{mol} / \mathrm{L} \mathrm{dp}$-ucMGP was associated with increased systolic and diastolic blood pressures and incident hypertension after 6 years of follow-up [59]. Up to now, no study investigated the combination of optimal vitamin $\mathrm{D}$ and $\mathrm{K}$ status in relation to coronary artery calcification and cardiovascular events after long-term follow-up. This would give valuable insight if vitamins $\mathrm{D}$ and $\mathrm{K}$ are involved in developing cardiovascular disease.

So far, two human intervention studies in healthy populations have investigated the combined effect of vitamins $\mathrm{D}$ and $\mathrm{K}$ on vascular function and calcification (Table 2) [60, $61]$. In postmenopausal women, after 3 years of supplementation $\left(1000 \mu \mathrm{g} / \mathrm{d}\right.$ vitamin $\mathrm{K}_{1}+320 \mathrm{IU}$ vitamin $\left.\mathrm{D}\right)$, the vitamin $\mathrm{D}+\mathrm{K}$ group maintained vessel wall characteristics of the carotid artery, whereas the control group and the vitamin D-only group significantly worsened over 3 years of followup [60]. However, vitamin $\mathrm{K}$ status was not measured as a marker of compliance to investigate what would have occurred following supplementation. Further, in a 3-year, double-blind, randomized controlled trial in older men and women free of clinical CVD, daily supplemental vitamin $\mathrm{K}$ in amounts achievable by high dietary intake of green, leafy vegetables $(500 \mu \mathrm{g} /$ day) combined with $600 \mathrm{mg}$ calcium carbonate and $10 \mu \mathrm{g}$ (400 IU) vitamin D did not result in lower coronary artery calcium progression as assessed by computerized tomography compared to the calcium + vitamin D group. In a subgroup analysis of participants who were $\geq 85 \%$ adherent to supplementation, there was less coronary artery calcium progression in the vitamin $\mathrm{K}+$ calcium and vitamin $\mathrm{D}$ groups than in the calcium and vitamin $\mathrm{D}$ group alone [61]; however, MGP carboxylation status was not determined. These data are hypothesis generating, and further studies are warranted to clarify the mechanism.

Among overweight type 2 diabetic patients with coronary heart disease, cosupplementation for 12 weeks of vitamins D
$(10 \mu \mathrm{g})$ and $\mathrm{K}(180 \mu \mathrm{g})$ and calcium $(1000 \mathrm{mg})$ had beneficial effects on maximum levels of left carotid intima-media thickness and insulin metabolism markers [62]; however, no effect on right intima-media thickness was found and the results could be a chance finding. Unfortunately, circulating markers of vitamin $\mathrm{K}$ concentrations and vitamin $\mathrm{K}$-dependent proteins were not taken into account to get a better mechanistic understanding.

Two trials studied the effect of vitamin $\mathrm{D}$ versus vitamin $\mathrm{D}+\mathrm{K}$ in nondialyzed CKD patients on vascular calcification and cardiovascular risk factors for 9 months $[63,64]$. In 42 CKD patients, the increase in carotid intima-media thickness (IMT) was significantly lower in the K (90 $\mu$ g menaquinone$7)+\mathrm{D}(10 \mu \mathrm{g}$ vitamin $\mathrm{D})$ group compared with the D-only group after 9 months [63]. Another small trial $(n=38)$ from the same research group did not show differences between the $\mathrm{D}$ versus $\mathrm{D}+\mathrm{K}$ groups on cardiovascular risk markers [64]. These few studies show some potential for the combined effect of vitamins $\mathrm{D}+\mathrm{K}$ versus $\mathrm{D}$ alone on subclinical CVD risk markers. It should be noted that very few clinical studies have been conducted in this field and that vitamin $\mathrm{D}+\mathrm{K}$ supplements have been often combined with different micronutrients making it difficult to solely pinpoint the effect of vitamin $\mathrm{D}+\mathrm{K}$. These limited studies indicate that joint supplementation might benefit cardiovascular health.

\section{Vitamins D and K with Glucose Metabolism and Inflammation}

Another pathway that might affect CVD risk is via disturbances in glucose metabolism. Among Iranian vitamin D-deficient women with polycystic ovary syndrome-a dysmetabolic disorder-cosupplementation of calcium (1000 mg) and vitamins D (400 IU) and $\mathrm{K}(180 \mu \mathrm{g})$ for 8 weeks improved markers of insulin metabolism and lipid concentrations compared to placebo [65]. The joint supplementation of vitamins $\mathrm{D}$ and $\mathrm{K}$ might improve insulin metabolism through an effect on upregulation of the insulin receptor genes, the regulation of insulin secretion from the pancreatic beta-cell, the enhancement of $\beta$-cell proliferation, and suppression of parathyroid hormone [66-69].

Further, another feature in which both vitamins D and $\mathrm{K}$ overlap is on inflammation, which is strongly related to the development of CVD and osteoporosis [70]. In the same Iranian clinical trial among vitamin D-deficient women with polycystic ovary syndrome, the joint supplementation of calcium with vitamins $\mathrm{D}$ and $\mathrm{K}$ had beneficial effects on endocrine and oxidative stress markers, however no effect on inflammatory markers [71].

\section{Effects of Long-Term Vitamin D Supplementation}

A large group of people uses both vitamin D and calcium for the prevention of falls and fractures. Given the fact that $25(\mathrm{OH}) \mathrm{D}$ is converted to $1,25(\mathrm{OH}) \mathrm{D}$, vitamin D supplementation stimulates the production of $1,25(\mathrm{OH}) \mathrm{D}$ [72]. This means that long-term vitamin $\mathrm{D}$ supplementation could promote the production of large amounts of vitamin K- 


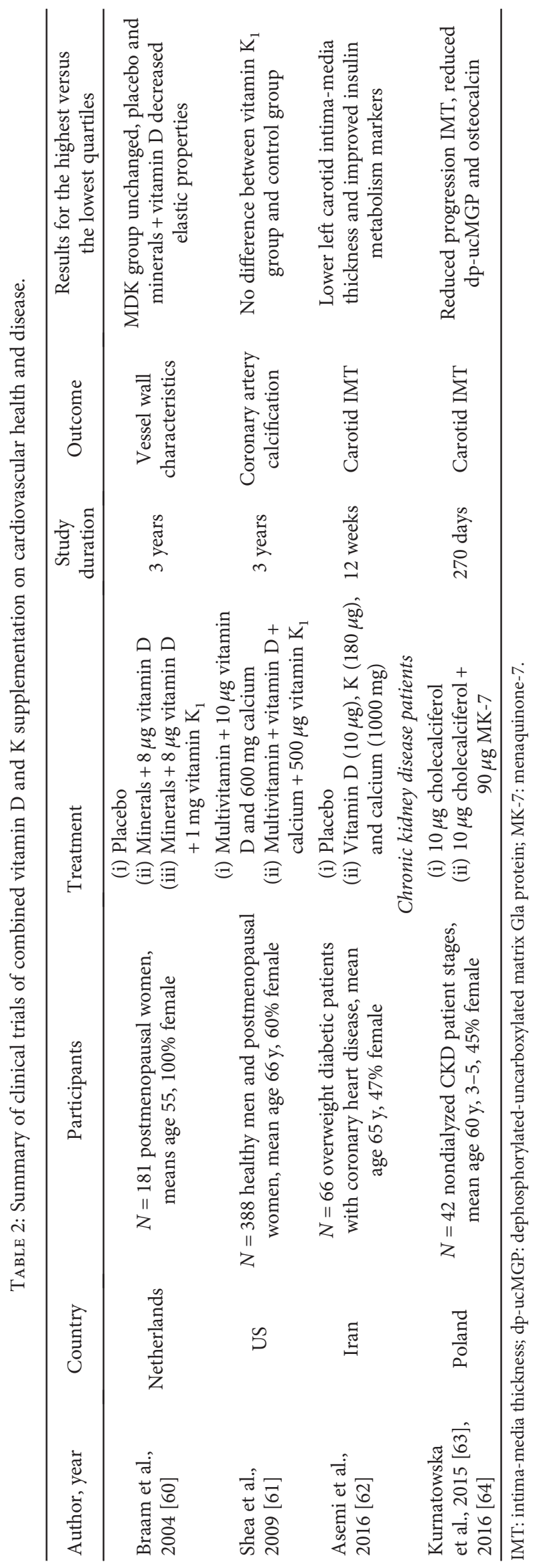




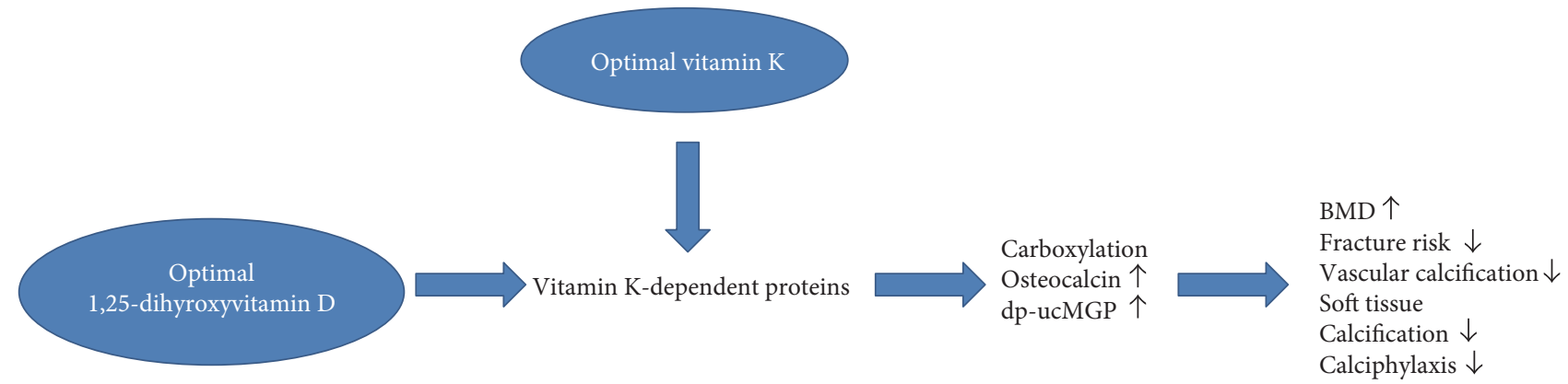

FIGURE 1: Simplified overview of potential synergy between vitamins D and $\mathrm{K}$ and bone and cardiovascular health. dp-ucMGP: dephosphorylated-uncarboxylated matrix Gla protein: BMD: bone mineral density. Genetic, molecular, cellular, and human evidence support that optimal concentrations of both vitamin D and vitamin $\mathrm{K}$ are beneficial for bone and cardiovascular health. Vitamin $\mathrm{K}$ is needed for the carboxylation of vitamin K-dependent proteins such as osteocalcin and matrix Gla protein, while vitamin D promotes the production of vitamin K-dependent protein concentrations. These vitamin K-dependent proteins are needed for extrahepatic organs such as the bone and the vascular system. This will result in bone mineralization and will inhibit soft tissue calcification, which will ultimately lead to lower risks of fractures and coronary heart disease.

dependent proteins, which remain inactive because there is not enough vitamin $\mathrm{K}$ to carboxylate (Figure 1). We propose a new hypothesis that if vitamin $\mathrm{D}$ concentrations are constantly high, there might not be enough vitamin $\mathrm{K}$ for activation of vitamin K-dependent proteins. Consequently, excess vitamin $\mathrm{D}$ diminishes the ability of vitamin $\mathrm{K}$ dependent proteins to function properly, to stimulate bone mineralization, and to inhibit soft tissue calcification.

Further, increasing vitamin D intake through dietary or supplemental source increases intestinal calcium absorption, particularly when combined with calcium supplementation, and promotes hypercalcemia [73]. In this context, a human trial was performed in older women who received either $1200 \mathrm{mg}$ calcium or $1200 \mathrm{mg}$ calcium and $800 \mathrm{IU}$ vitamin D per day over a 12-week period [74]. At the end of the 12 weeks, neither group observed a change in calcium concentrations, meaning that calcium was either excreted or stored somewhere. Increased calcium intake by itself may not be problematic as long as there is a steady state between optimal vitamin $\mathrm{D}$ and vitamin $\mathrm{K}$ concentrations. The disbalance between vitamin $\mathrm{D}$ and vitamin $\mathrm{K}$ promotes an environment in which excess calcium will be deposited into our vascular tissue instead of bone. The migration of calcification into the vascular tissue is described by the double burden of atherosclerosis and osteoporosis [75-77]. Additionally, as vitamin D increases calcium absorption, it might also promote hypercalcemia as seen in the Women's Health Initiative, which found a $24 \%$ higher risk of myocardial infarction in individuals taking calcium and vitamin D supplements and a greater risk for urinary tract stone occurrence: hazard ratio 1.17 (95\% CI 1.02, 1.34) [11, 13, 14]. One prospective study found that higher $1,25(\mathrm{OH}) \mathrm{D}$ concentrations were strongly associated with the incidence of hypertension, while $25(\mathrm{OH}) \mathrm{D}$ was inversely associated with hypertension risk [78]. Higher 1,25(OH)D was associated with lower urinary calcium excretion, which could mean that the calcium meant for bone is stored somewhere else. Unfortunately, vitamin $\mathrm{K}$ status was not measured which would have given valuable insight into the association between vitamins $\mathrm{D}$ and $\mathrm{K}$ with calcium excretion.

\section{Calciphylaxis and Vitamin K Antagonist Use}

Calciphylaxis is a syndrome of calcification of the blood vessels, coagulopathy, and skin necrosis. It is seen mostly in patients with end-stage kidney disease, but can occur in the absence of kidney failure. Vitamin K antagonist use may contribute to its development [79]. The syndrome may cause a substantial morbidity and mortality. However, it should be acknowledged that the term calciphylaxis refers to a heterogeneous disorder that is characterized by soft tissue and vascular necrosis and has a clinical presentation from mild to severe. The underlying causes of calciphylaxis are not well understood; however, reported risk factors include female sex, obesity, elevated calcium* ${ }^{*}$ phosphate product, warfarin use, and vitamin D derivatives, for example, calcitriol, calcium-based binders, or systemic steroids, low blood albumin concentrations, and type 2 diabetes [80]. A recent study among patients with hemodialysis with calciphylaxis versus hemodialysis showed that cases had higher plasma uncarboxylated MGP concentrations than controls, which suggest a role of MGP in the pathophysiology of calciphylaxis. The fraction of total MGP that was carboxylated was also lower in cases than in controls. Vitamin K deficiency-mediated reduction in relative carboxylated MGP concentration may play a role in the pathogenesis of calciphylaxis [81]. This could be further mediated by the combined use of vitamin $\mathrm{D}$ derivatives and warfarin. Further, another study indicated that vitamin $\mathrm{K}$ antagonist use predisposes to the development of calciphylaxis in end-stage renal disease [82]. More evidence on the combined role of vitamin K antagonist use and vitamin D on bone and cardiovascular health is urgently needed.

\section{Vitamin D and K Supplementation}

Based on the current body of evidence, there is not enough evidence to recommend combined vitamin D and $\mathrm{K}$ supplementation for the prevention and treatment of osteoporosis. Most trials studied low-dose vitamin D in isolation (400-800 IU daily), which demonstrated only 
modest or null effects on BMD and fracture prevention in mostly $\geq 65$ years postmenopausal women [6-8]. Large clinical trials of moderate-high dose ( $\geq 800 \mathrm{IU}$ daily) vitamin $\mathrm{D}$ supplementation (cholecalciferol) are currently in progress.

The most widely used vitamin $\mathrm{K}$ form for supplementation is vitamin $\mathrm{K}_{2}$ and more specifically menaquinone- 4 and menaquinone-7. Menaquinone- 4 is more used in trials with bone outcomes, while menaquinone-7 is more in trials with cardiovascular outcomes with dosages between 90-360 $\mu \mathrm{g}$. Menaquinone-7 has a higher bioavailability and may be of particular importance for extrahepatic tissue [83]. No cut-off value for vitamin $\mathrm{K}$ status nor vitamin $\mathrm{K}$ supplementation is available yet. Future studies are needed to determine whether vitamin $\mathrm{D}$ combined with vitamin $\mathrm{K}$ rich foods or vitamin $\mathrm{K}$ supplementation could improve bone and cardiovascular health.

\section{Recommendations for Future Research}

The recommendations for future research are as follows:

(i) Evaluate the role of vitamin D administration in vitamin $\mathrm{K}$-dependent proteins in human populations

(ii) Question the possible long-term consequences of high-dose vitamin D supplementation

(iii) Assess the combined role of vitamin $\mathrm{K}$ antagonist use and vitamin $\mathrm{D}$ in bone and cardiovascular health

(iv) Investigate the joint supplementation of vitamins D and $\mathrm{K}$ on hard clinical endpoints

\section{Conclusion}

Taken together, animal and human studies suggest that optimal concentrations of both vitamin $\mathrm{D}$ and vitamin $\mathrm{K}$ are beneficial for bone and cardiovascular health as supported by genetic, molecular, cellular, and some human studies. However, vitamin D and calcium supplementation along with vitamin $\mathrm{K}$ deficiency might also induce longterm soft tissue calcification and CVD, particularly in vitamin $\mathrm{K}$ antagonist users and other high-risk populations. At this moment, we should be careful about supplementing high-dose vitamin $\mathrm{D}$, unless indicated differently. More clinical data about the potential interplay between vitamin $\mathrm{D}$ and vitamin $\mathrm{K}$ metabolism is urgently needed before broader treatment recommendations can be given.

The consumption of a well-balanced diet is key for population-based primary prevention of chronic diseases. As more is discovered about the powerful combination of vitamins $\mathrm{D}$ and $\mathrm{K}$, it gives a renewed reason to eat a healthy diet including a variety of foods such as vegetables and fermented dairy for bone and cardiovascular health.

\section{Conflicts of Interest}

The authors declare that there is no conflict of interest regarding the publication of this paper.

\section{References}

[1] G. Skeie, T. Braaten, A. Hjartaker et al., "Use of dietary supplements in the European prospective investigation into cancer and nutrition calibration study," European Journal of Clinical Nutrition, vol. 63, Supplement 4, pp. S226-S238, 2009.

[2] A. Spiro and J. L. Buttriss, "Vitamin D: an overview of vitamin D status and intake in Europe," Nutrition Bulletin, vol. 39, pp. 322-350, 2014.

[3] EFSA Panel on Dietetic Products, NaA, "Scientific opinion on the tolerable upper intake level of vitamin D," EFSA Journal, vol. 10, p. 2813, 2012.

[4] A. Zittermann, J. B. Ernst, S. Prokop et al., "Effect of vitamin D on all-cause mortality in heart failure (EVITA): a 3-year randomized clinical trial with 4000 IU vitamin D daily," European Heart Journal, vol. 38, no. 29, pp. 2279-2286, 2017.

[5] J. S. Adams, B. Rafison, S. Witzel et al., "Regulation of the extrarenal CYP27B1-hydroxylase," The Journal of Steroid Biochemistry and Molecular Biology, vol. 144, Part A, pp. 2227, 2014.

[6] A. Dusso, A. Brown, and E. Slatopolsky, "Extrarenal production of calcitriol," Seminars in Nephrology, vol. 14, pp. 144155, 1994.

[7] H. S. Cross and E. Kallay, "Nutritional regulation of extrarenal vitamin D hydroxylase expression - potential application in tumor prevention and therapy," Future Oncology, vol. 1, pp. 415-424, 2005.

[8] J. C. Fleet, "The role of vitamin D in the endocrinology controlling calcium homeostasis," Molecular and Cellular Endocrinology, vol. 17, pp. 30221-30226, 2017.

[9] G. Bjelakovic, L. L. Gluud, D. Nikolova et al., "Vitamin D supplementation for prevention of mortality in adults," Cochrane Database of Systematic Reviews, article CD007470, 2014.

[10] A. Avenell, J. C. Mak, and D. O'Connell, "Vitamin D and vitamin $\mathrm{D}$ analogues for preventing fractures in postmenopausal women and older men," Cochrane Database of Systematic Reviews, article CD000227, 2014.

[11] M. J. Bolland, A. Grey, A. Avenell, G. D. Gamble, and I. R. Reid, "Calcium supplements with or without vitamin D and risk of cardiovascular events: reanalysis of the Women's Health Initiative limited access dataset and meta-analysis," British Medical Journal, vol. 342, article d2040, 2011.

[12] I. Thiele, J. Linseisen, C. Meisinger et al., "Associations between calcium and vitamin D supplement use as well as their serum concentrations and subclinical cardiovascular disease phenotypes," Atherosclerosis, vol. 241, pp. 743-751, 2015.

[13] D. Challoumas, A. Stavrou, A. Pericleous, and G. Dimitrakakis, "Effects of combined vitamin D-calcium supplements on the cardiovascular system: should we be cautious?," Atherosclerosis, vol. 238, pp. 388-398, 2015.

[14] R. B. Wallace, J. Wactawski-Wende, M. J. O'Sullivan et al., "Urinary tract stone occurrence in the Women's Health Initiative (WHI) randomized clinical trial of calcium and vitamin D supplements," The American Journal of Clinical Nutrition, vol. 94, pp. 270-277, 2011.

[15] S. L. Booth and A. RajabiAl, "Determinants of vitamin K status in humans," Vitamins and Hormones, vol. 78, pp. 1-22, 2008.

[16] M. J. Shearer and P. Newman, "Recent trends in the metabolism and cell biology of vitamin $\mathrm{K}$ with special reference to vitamin K cycling and MK-4 biosynthesis," Journal of Lipid Research, vol. 55, pp. 345-362, 2014. 
[17] S. A. Lanham-New, "Importance of calcium, vitamin D and vitamin $\mathrm{K}$ for osteoporosis prevention and treatment," The Proceedings of the Nutrition Society, vol. 67, pp. 163-176, 2008.

[18] D. Turck, J. L. Bresson, B. Burlingame et al., "EFSA panel on dietetic products, nutrition and allergies. Dietary reference values for vitamin K," EFSA Journal, vol. 15, p. 4780, 2017.

[19] S. L. Booth, G. Dallal, M. K. Shea, C. Gundberg, J. W. Peterson, and B. Dawson-Hughes, "Effect of vitamin K supplementation on bone loss in elderly men and women," The Journal of Clinical Endocrinology and Metabolism, vol. 93, pp. 1217-1223, 2008.

[20] A. J. Ballegooijenvan and J. W. Beulens, "The role of vitamin K status in cardiovascular health: evidence from observational and clinical studies," Current Nutrition Reports, pp. 1-9, 2017.

[21] X. Fu, X. D. Wang, H. Mernitz, R. Wallin, M. K. Shea, and S. L. Booth, "9-cis retinoic acid reduces 1alpha,25-dihydroxycholecalciferol-induced renal calcification by altering vitamin K-dependent gamma-carboxylation of matrix gamma-carboxyglutamic acid protein in A/J male mice," The Journal of Nutrition, vol. 138, pp. 2337-2341, 2008.

[22] N. C. Arbour, H. M. Darwish, and H. F. DeLuca, "Transcriptional control of the osteocalcin gene by 1,25-dihydroxyvitamin D-2 and its 24-epimer in rat osteosarcoma cells," Biochimica et Biophysica Acta, vol. 1263, pp. 147-153, 1995.

[23] Y. Seyama, M. Horiuch, M. Hayashi, and Y. Kanke, "Effect of vitamin $\mathrm{K} 2$ on experimental calcinosis induced by vitamin D2 in rat soft tissue," International Journal for Vitamin and Nutrition Research, vol. 66, pp. 36-38, 1996.

[24] E. C. Breen, A. J. Wijnenvan, J. B. Lian, G. S. Stein, and J. L. Stein, "In vivo occupancy of the vitamin $\mathrm{D}$ responsive element in the osteocalcin gene supports vitamin D-dependent transcriptional upregulation in intact cells," Proceedings of the National Academy of Sciences of the United States of America, vol. 91, pp. 12902-12906, 1994.

[25] J. D. Fraser and P. A. Price, "Induction of matrix Gla protein synthesis during prolonged 1,25-dihydroxyvitamin D3 treatment of osteosarcoma cells," Calcified Tissue International, vol. 46, pp. 270-279, 1990.

[26] N. Miyake, K. Hoshi, Y. Sano, K. Kikuchi, K. Tadano, and Y. Koshihara, "1,25-Dihydroxyvitamin D3 promotes vitamin K2 metabolism in human osteoblasts," Osteoporosis International, vol. 12, pp. 680-687, 2001.

[27] P. I. Karl, D. L. Carnes, and P. A. Friedman, "Effects of 1,25-dihydroxycholecalciferol administration on the rat renal vitamin K-dependent carboxylating system," FEBS Letters, vol. 192, pp. 243-246, 1985.

[28] D. D. Bikle, "Vitamin D metabolism, mechanism of action, and clinical applications," Chemistry \& Biology, vol. 21, pp. 319-329, 2014.

[29] Y. Koshihara and K. Hoshi, "Vitamin K2 enhances osteocalcin accumulation in the extracellular matrix of human osteoblasts in vitro," Journal of Bone and Mineral Research, vol. 12, pp. 431-438, 1997.

[30] P. A. Price and S. A. Baukol, "1,25-Dihydroxyvitamin D3 increases synthesis of the vitamin K-dependent bone protein by osteosarcoma cells," The Journal of Biological Chemistry, vol. 255, pp. 11660-11663, 1980.

[31] P. A. Price and S. A. Baukol, "1,25-dihydroxyvitamin D3 increases serum levels of the vitamin K-dependent bone protein," Biochemical and Biophysical Research Communications, vol. 99, pp. 928-935, 1981.
[32] S. A. Kerner, R. A. Scott, and J. W. Pike, "Sequence elements in the human osteocalcin gene confer basal activation and inducible response to hormonal vitamin D3," Proceedings of the National Academy of Sciences of the United States of America, vol. 86, pp. 4455-4459, 1989.

[33] Y. Koshihara, K. Hoshi, H. Ishibashi, and M. Shiraki, "Vitamin $\mathrm{K} 2$ promotes 1alpha,25(OH)2 vitamin D3-induced mineralization in human periosteal osteoblasts," Calcified Tissue International, vol. 59, pp. 466-473, 1996.

[34] I. N. Sergeev and A. W. Norman, "Vitamin K-dependent gamma-carboxylation of the 1,25-dihydroxyvitamin D3 receptor," Biochemical and Biophysical Research Communications, vol. 189, pp. 1543-1547, 1992.

[35] R. Sanguineti, F. Monacelli, A. Parodi et al., "Vitamins D3 and K2 may partially counterbalance the detrimental effects of pentosidine in ex vivo human osteoblasts," Journal of Biological Regulators and Homeostatic Agents, vol. 30, pp. 713-726, 2016.

[36] A. Gigante, M. Torcianti, E. Boldrini et al., "Vitamin K and D association stimulates in vitro osteoblast differentiation of fracture site derived human mesenchymal stem cells," Journal of Biological Regulators and Homeostatic Agents, vol. 22, pp. 35-44, 2008.

[37] K. Hara, Y. Akiyama, T. Tomiuga, M. Kobayashi, T. Nakamura, and T. Tajima, "Influence of vitamin D3 on inhibitory effect of vitamin K2 on bone loss in ovariectomized rats," Nihon Yakurigaku Zasshi, vol. 104, pp. 101109, 1994.

[38] S. Matsunaga, H. Ito, and T. Sakou, "The effect of vitamin K and D supplementation on ovariectomy-induced bone loss," Calcified Tissue International, vol. 65, pp. 285-289, 1999.

[39] J. Iwamoto, A. Seki, Y. Sato, H. Matsumoto, T. Tadeda, and J. $\mathrm{K}$. Yeh, "Vitamin K2 promotes bone healing in a rat femoral osteotomy model with or without glucocorticoid treatment," Calcified Tissue International, vol. 86, pp. 234-241, 2010.

[40] M. Fusaro, S. Giannini, M. Gallieni et al., "Calcimimetic and vitamin $\mathrm{D}$ analog use in hemodialyzed patients is associated with increased levels of vitamin K dependent proteins," Endocrine, vol. 51, pp. 333-341, 2016.

[41] M. Tamatani, S. Morimoto, M. Nakajima et al., "Decreased circulating levels of vitamin $\mathrm{K}$ and 25-hydroxyvitamin $\mathrm{D}$ in osteopenic elderly men," Metabolism, vol. 47, pp. 195-199, 1998.

[42] A. C. Torbergsen, L. O. Watne, T. B. Wyller et al., "Vitamin K1 and $25(\mathrm{OH}) \mathrm{D}$ are independently and synergistically associated with a risk for hip fracture in an elderly population: a case control study," Clinical Nutrition, vol. 34, pp. 101-106, 2015.

[43] T. E. Finnes, C. M. Lofthus, H. E. Meyer et al., "A combination of low serum concentrations of vitamins $\mathrm{K} 1$ and D is associated with increased risk of hip fractures in elderly Norwegians: a NOREPOS study," Osteoporosis International, vol. 27, pp. 1645-1652, 2016.

[44] A. Vignini, L. Nanetti, F. Raffaelli et al., "Effect of supplementation with fortified olive oil on biochemical markers of bone turnover in healthy women," Mediterranean Journal of Nutrition and Metabolism, vol. 1, pp. 117-120, 2008.

[45] T. Ushiroyama, A. Ikeda, and M. Ueki, "Effect of continuous combined therapy with vitamin $\mathrm{K}(2)$ and vitamin $\mathrm{D}(3)$ on bone mineral density and coagulofibrinolysis function in postmenopausal women," Maturitas, vol. 41, pp. 211-221, 2002. 
[46] J. Iwamoto, T. Takeda, and S. Ichimura, "Effect of combined administration of vitamin D3 and vitamin $\mathrm{K} 2$ on bone mineral density of the lumbar spine in postmenopausal women with osteoporosis," Journal of Orthopaedic Science, vol. 5, pp. 546$551,2000$.

[47] C. Bolton-Smith, M. E. McMurdo, C. R. Paterson et al., "Two-year randomized controlled trial of vitamin K1 (phylloquinone) and vitamin D3 plus calcium on the bone health of older women," Journal of Bone and Mineral Research, vol. 22, pp. 509-519, 2007.

[48] L. A. Braam, M. H. Knapen, P. Geusens et al., "Vitamin K1 supplementation retards bone loss in postmenopausal women between 50 and 60 years of age," Calcified Tissue International, vol. 73, pp. 21-26, 2003.

[49] S. H. Je, N. S. Joo, B. H. Choi et al., "Vitamin K supplement along with vitamin $\mathrm{D}$ and calcium reduced serum concentration of undercarboxylated osteocalcin while increasing bone mineral density in Korean postmenopausal women over sixty-years-old," Journal of Korean Medical Science, vol. 26, pp. 1093-1098, 2011.

[50] L. Mazzanti, M. Battino, L. Nanetti et al., "Effect of 1-year dietary supplementation with vitaminized olive oil on markers of bone turnover and oxidative stress in healthy post-menopausal women," Endocrine, vol. 50, pp. 326-334, 2015.

[51] Y. Sato, T. Kanoko, K. Satoh, and J. Iwamoto, "Menatetrenone and vitamin D2 with calcium supplements prevent nonvertebral fracture in elderly women with Alzheimer's disease," Bone, vol. 36, pp. 61-68, 2005.

[52] E. M. O'Connor, G. Grealy, J. McCarthy et al., "Effect of phylloquinone (vitamin K1) supplementation for 12 months on the indices of vitamin $\mathrm{K}$ status and bone health in adult patients with Crohn's disease," The British Journal of Nutrition, vol. 112, pp. 1163-1174, 2014.

[53] N. Binkley, J. Harke, D. Krueger et al., "Vitamin K treatment reduces undercarboxylated osteocalcin but does not alter bone turnover, density, or geometry in healthy postmenopausal North American women," Journal of Bone and Mineral Research, vol. 24, pp. 983-991, 2009.

[54] A. M. Cheung, L. Tile, Y. Lee et al., "Vitamin K supplementation in postmenopausal women with osteopenia (ECKO trial): a randomized controlled trial," PLoS Medicine, vol. 5, article e196, 2008.

[55] K. Yonemura, H. Fukasawa, Y. Fujigaki, and A. Hishida, "Protective effect of vitamins $\mathrm{K} 2$ and D3 on prednisolone-induced loss of bone mineral density in the lumbar spine," American Journal of Kidney Diseases, vol. 43, pp. 53-60, 2004.

[56] L. J. Schurgers, E. C. Cranenburg, and C. Vermeer, "Matrix Gla-protein: the calcification inhibitor in need of vitamin K," Thrombosis and Haemostasis, vol. 100, pp. 593-603, 2008.

[57] P. A. Price, S. A. Faus, and M. K. Williamson, "Warfarininduced artery calcification is accelerated by growth and vitamin D," Arteriosclerosis, Thrombosis, and Vascular Biology, vol. 20, pp. 317-327, 2000.

[58] O. Mayer Jr., J. Seidlerova, P. Wohlfahrt et al., "Synergistic effect of low $\mathrm{K}$ and $\mathrm{D}$ vitamin status on arterial stiffness in a general population," The Journal of Nutritional Biochemistry, vol. 46, pp. 83-89, 2017.

[59] A. J. Ballegooijenvan, A. Cepelis, M. Visser, I. A. Brouwer, N. M. Schoorvan, and J. W. Beulens, "Joint association of low vitamin $\mathrm{D}$ and vitamin $\mathrm{K}$ status with blood pressure and hypertension," Hypertension, vol. 69, pp. 1165-1172, 2017.
[60] L. A. Braam, A. P. Hoeks, F. Brouns, K. Hamulyák, M. J. Gerichhausen, and C. Vermeer, "Beneficial effects of vitamins $\mathrm{D}$ and $\mathrm{K}$ on the elastic properties of the vessel wall in postmenopausal women: a follow-up study," Thrombosis and Haemostasis, vol. 91, pp. 373-380, 2004.

[61] M. K. Shea, C. J. O'Donnell, U. Hoffmann et al., "Vitamin K supplementation and progression of coronary artery calcium in older men and women," The American Journal of Clinical Nutrition, vol. 89, pp. 1799-1807, 2009.

[62] Z. Asemi, F. Raygan, F. Bahmani et al., "The effects of vitamin $\mathrm{D}, \mathrm{K}$ and calcium co-supplementation on carotid intimamedia thickness and metabolic status in overweight type 2 diabetic patients with CHD," The British Journal of Nutrition, vol. 116, pp. 286-293, 2016.

[63] I. Kurnatowska, P. Grzelak, A. Masajtis-Zagajewska et al., "Effect of vitamin $\mathrm{K} 2$ on progression of atherosclerosis and vascular calcification in nondialyzed patients with chronic kidney disease stages 3-5," Polskie Archiwum Medycyny Wewnętrznej, vol. 125, pp. 631-640, 2015.

[64] I. Kurnatowska, P. Grzelak, A. Masajtis-Zagajewska et al., "Plasma desphospho-uncarboxylated matrix Gla protein as a marker of kidney damage and cardiovascular risk in advanced stage of chronic kidney disease," Kidney \& Blood Pressure Research, vol. 41, pp. 231-239, 2016.

[65] M. Karamali, M. Ashrafi, M. Razavi et al., "The effects of calcium, vitamins $\mathrm{D}$ and $\mathrm{K}$ co-supplementation on markers of insulin metabolism and lipid profiles in vitamin Ddeficient women with polycystic ovary syndrome," Experimental and Clinical Endocrinology \& Diabetes, vol. 125, pp. 316-321, 2017.

[66] B. Maestro, S. Molero, S. Bajo, N. Dávila, and C. Calle, “Transcriptional activation of the human insulin receptor gene by 1,25-dihydroxyvitamin D(3)," Cell Biochemistry and Function, vol. 20, pp. 227-232, 2002.

[67] I. N. Sergeev and W. B. Rhoten, "1,25-Dihydroxyvitamin D3 evokes oscillations of intracellular calcium in a pancreatic beta-cell line," Endocrinology, vol. 136, pp. 2852-2861, 1995.

[68] N. Sakamoto, I. Wakabayashi, and K. Sakamoto, "Low vitamin $\mathrm{K}$ intake effects on glucose tolerance in rats," International Journal for Vitamin and Nutrition Research, vol. 69, pp. 2731, 1999.

[69] M. Yoshida, P. F. Jacques, J. B. Meigs et al., "Effect of vitamin K supplementation on insulin resistance in older men and women," Diabetes Care, vol. 31, pp. 2092-2096, 2008.

[70] G. Crepaldi and S. Maggi, "Epidemiologic link between osteoporosis and cardiovascular disease," Journal of Endocrinological Investigation, vol. 32, pp. 2-5, 2009.

[71] M. Razavi, M. Jamilian, M. Karamali, F. Bahmani, E. Aghadavod, and Z. Asemi, "The effects of vitamin D-Kcalcium co-supplementation on endocrine, inflammation, and oxidative stress biomarkers in vitamin D-deficient women with polycystic ovary syndrome: a randomized, double-blind, placebo-controlled trial," Hormone and Metabolic Research, vol. 48, pp. 446-451, 2016.

[72] P. Lips, A. Wiersinga, F. C. Ginkelvan et al., "The effect of vitamin D supplementation on vitamin D status and parathyroid function in elderly subjects," The Journal of Clinical Endocrinology and Metabolism, vol. 67, pp. 644-650, 1988.

[73] M. Peacock, "Calcium metabolism in health and disease," Clinical Journal of the American Society of Nephrology, vol. 5, Supplement 1, pp. S23-S30, 2010. 
[74] H. A. Bischoff, H. B. Stahelin, W. Dick et al., "Effects of vitamin $\mathrm{D}$ and calcium supplementation on falls: a randomized controlled trial," Journal of Bone and Mineral Research, vol. 18, pp. 343-351, 2003.

[75] D. Uylden, M. T. Nurmohamed, L. H. Tuylvan, H. G. Raterman, and W. F. Lems, "(Sub)clinical cardiovascular disease is associated with increased bone loss and fracture risk; a systematic review of the association between cardiovascular disease and osteoporosis," Arthritis Research \& Therapy, vol. 13, article R5, 2011.

[76] S. K. Seo, B. H. Yun, E. B. Noe, J. W. Suh, Y. S. Choi, and B. S. Lee, "Decreased bone mineral density is associated with coronary atherosclerosis in healthy postmenopausal women," Obstetrics \& Gynecology Science, vol. 58, pp. 144-149, 2015.

[77] R. Zhou, H. Zhou, M. Cui et al., "Association between aortic calcification and the risk of osteoporosis in a Chinese cohort: the Chongqing osteoporosis study," Calcified Tissue International, vol. 93, pp. 419-425, 2013.

[78] A. J. Ballegooijenvan, R. T. Gansevoort, H. J. LambersHeerspink et al., "Plasma 1,25-dihydroxyvitamin D and the risk of developing hypertension: the prevention of renal and vascular end-stage disease study," Hypertension, vol. 66, pp. 563-570, 2015.

[79] T. Coates, G. S. Kirkland, R. B. Dymock et al., "Cutaneous necrosis from calcific uremic arteriolopathy," American Journal of Kidney Diseases, vol. 32, pp. 384-391, 1998.

[80] G. Arseculeratne, A. T. Evans, and S. M. Morley, "Calciphylaxis-a topical overview," Journal of the European Academy of Dermatology and Venereology, vol. 20, pp. 493-502, 2006.

[81] S. U. Nigwekar, D. B. Bloch, R. M. Nazarian et al., "Vitamin Kdependent carboxylation of matrix Gla protein influences the risk of calciphylaxis," Journal of the American Society of Nephrology, vol. 28, no. 6, pp. 1717-1722, 2017.

[82] P. A. Galloway, R. El-Damanawi, V. Bardsley et al., "Vitamin K antagonists predispose to calciphylaxis in patients with endstage renal disease," Nephron, vol. 129, pp. 197-201, 2015.

[83] T. Sato, L. J. Schurgers, and K. Uenishi, "Comparison of menaquinone- 4 and menaquinone- 7 bioavailability in healthy women," Nutrition Journal, vol. 11, p. 93, 2012. 




The Scientific World Journal
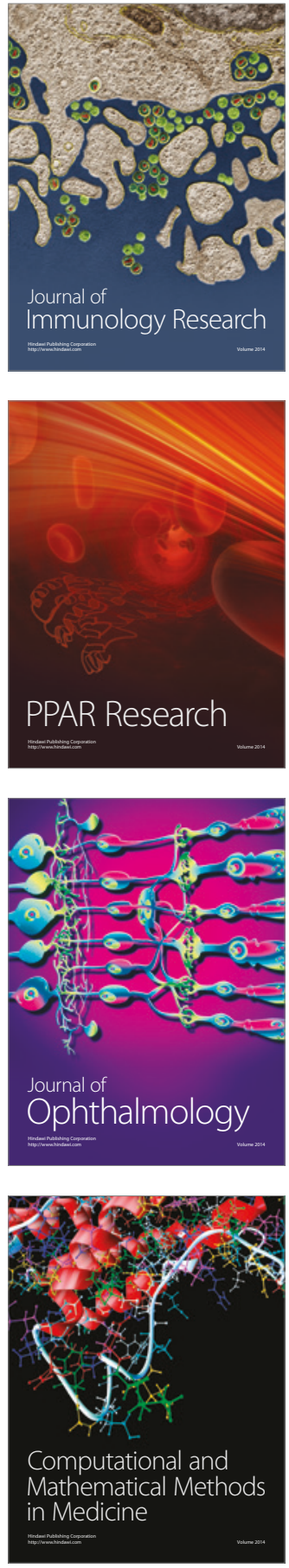

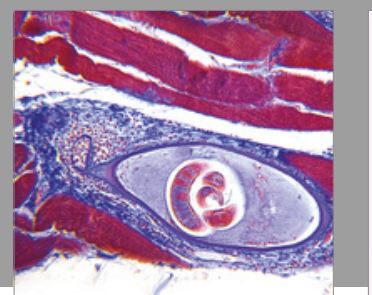

Gastroenterology Research and Practice


\section{Hindawi}

Submit your manuscripts at

https://www.hindawi.com

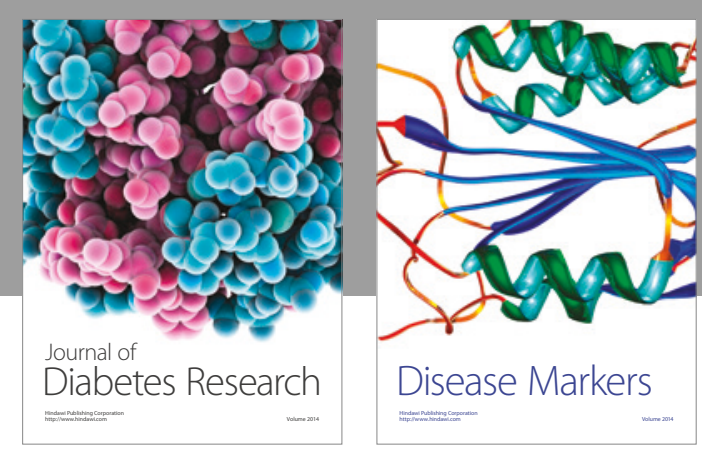

Disease Markers
